\title{
Extreme lateral transodontoid approach to the ventral craniocervical junction: cadaveric dissection and case illustrations
}

\author{
Gmaan Alzhrani, MD, FRCSC, Yair M. Gozal, MD, PhD, llyas Eli, MD, Walavan Sivakumar, MD, \\ Amol Raheja, MBBS, Douglas L. Brockmeyer, MD, and William T. Couldwell, MD, PhD
}

Department of Neurosurgery, Clinical Neurosciences Center, University of Utah, Salt Lake City, Utah

OBJECTIVE Surgical treatment of pathological processes involving the ventral craniocervical junction (CCJ) traditionally involves anterior and posterolateral skull base approaches. In cases of bilateral extension, when lesions extend beyond the midline to the contralateral side, a unilateral corridor may result in suboptimal resection. In these cases, the lateral extent of the tumor will prevent extirpation of the lesion via anterior surgical approaches. The authors describe a unilateral operative corridor developed along an extreme lateral trajectory to the anterior aspect of the clival and upper cervical dura, allowing exposure and resection of tumor on the contralateral side. This approach is used when the disease involves the bone structures inherent to stability at the anterior CCJ.

METHODS To achieve exposure of the ventral CCJ, an extreme lateral transcondylar transodontoid (ELTO) approach was performed with transposition of the ipsilateral vertebral artery, followed by drilling of the $\mathrm{C} 1$ anterior arch. Resection of the odontoid process allowed access to the contralateral component of lesions across the midline to the region of the extracranial contralateral vertebral artery, maximizing resection.

RESULTS Exposure and details of the surgical procedure were derived from anatomical cadavers. At the completion of cadaveric dissection, morphometric measurements of the relevant anatomical landmarks were obtained. Illustrative case examples for approaching ventral CCJ chordomas via the ELTO approach are presented.

CONCLUSIONS The ELTO approach provides a safe and direct surgical corridor to treat complex lesions at the ventral CCJ with bilateral extension through a single operative corridor. This approach can be combined with other lateral approaches or posterior infratemporal approaches to remove more extensive lesions involving the rostral clivus, jugular foramen, and temporal bone.

https://thejns.org/doi/abs/10.3171/2018.4.JNS172935

KEYWORDS extreme lateral transodontoid approach; ELTO approach; craniocervical junction; tumor; clival chordoma; lateral skull base approach

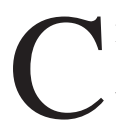

HORDOMAS constitute $0.2 \%$ of all central nervous system tumors and $1 \%-4 \%$ of all bone cancers. With an annual incidence of $0.08 / 1,000,000$ people, chordomas account for $30 \%-40 \%$ of skull base lesions involving the clivus and craniovertebral junction., ${ }^{4,142} \mathrm{Com}-$ plete resection is the current standard of care for skull base chordomas, but extirpation is often complicated by their deep-seated ventral location, their proximity to vital neurovascular structures, and their locally infiltrative nature. In some cases, bilateral extension across the midline to the contralateral side contributes to suboptimal resection. Giv- en the complexity of the anatomical relationships between the occipital bone, atlas, axis, and surrounding ligaments and musculature of the craniocervical junction (CCJ), lesions located in the ventral aspect of the CCJ represent a surgical challenge.

The surgical corridor for lesions located in the clivus and ventral aspect of the CCJ has evolved over time from ventral-based approaches (transoral, transfacial, and frontal transbasal) ${ }^{6,25,28}$ to posterolateral-based approaches (far lateral and extreme lateral paracondylar).,17,30,32 Over the past decade, the endoscopic endonasal approach to the cli-

ABBREVIATIONS CCJ = craniocervical junction; ELTC = extreme lateral transcondylar; ELTO = extreme lateral transodontoid; PICA = posterior inferior cerebellar artery; $\mathrm{VA}=$ vertebral artery.

SUBMITTED November 21, 2017. ACCEPTED April 5, 2018.

INCLUDE WHEN CITING Published online September 14, 2018; DOI: 10.3171/2018.4.JNS172935. 
vus and ventral CCJ has been explored as an alternative to open anterior approaches, offering equivalent resection with less invasiveness. ${ }^{10,16,29}$ In cases in which there is significant lateral extension, however, anterior surgical approaches do not allow removal of the lateral portion of the tumor, and a combined anterior and posterolateral approach is often required to achieve gross-total resection. ${ }^{18}$ Furthermore, a posterolateral approach has numerous additional benefits, including 1) early visualization of the vertebral artery (VA), posterior inferior cerebellar artery (PICA), and vertebrobasilar junction; 2) optimal vascular control with tumor dissection; 3) clear demarcation of the brainstem-tumor interface; 4) direct access to lateral tumor extension; 5) better dural repair with a decreased risk of CSF leakage; 6) no communication between the unsterile sinonasal cavity and the immunologically privileged intracranial compartment; and 7) avoidance of velopharyngeal dysfunction, which is commonly encountered in midline approaches. ${ }^{29,30} \mathrm{We}$ describe a lateral skull base approach to the ventral CCJ illustrated by our cadaveric dissection and surgical cases. We have used this approach to treat ventral CCJ chordomas (both intra- and extradural) with bilateral extension involving the lower clivus, $\mathrm{C} 1$ anterior arch, and odontoid process. Coined the extreme lateral transodontoid (ELTO) approach by the senior author, this technique uses a unilateral operative corridor developed along an extreme lateral trajectory to the anterior aspect of the clival and upper cervical dura, enabling exposure of the contralateral side.

\section{Methods \\ Materials}

We performed 7 cadaveric dissections using standard microsurgical instruments in 6 uninjected and 1 latexinjected and formalin-fixed adult cadaveric heads. The specimens were maintained in surgical position using a table-mounted Mayfield head clamp. An operating microscope and electric drills with cutting and diamond burrs were used in all dissections. Morphometric distances between relevant anatomical landmarks were measured. The surgical technique used during cadaveric dissection mimicked that used in our patients, except for the omission of occipitocervical fusion (Fig. 1).

\section{Surgical Technique}

The operative technique used for radical surgical decompression of ventral skull base chordomas is a unilateral ELTO approach, a more aggressive modification of the conventional extreme lateral transcondylar (ELTC) approach. The side that is most involved by the lesion is used as the side of approach. The approach enables excellent visualization of the ipsilateral and contralateral parts of the lesion when the anterior bony elements (lower clivus, anterior $\mathrm{C} 1 \mathrm{arch}$, and odontoid) are removed and allows safe tumor removal through one approach instead of bilateral approaches. Preoperative CT angiography is usually performed to evaluate the VA anatomy and assess vascular dominance. Intraoperative electrophysiological monitoring is routinely employed to assess somatosensory evoked potentials, motor evoked potentials, auditory brainstem evoked potentials, and the facial nerve and lower cranial nerves (IX-XII). The key operative concepts, which can expand the operative corridor for large invasive clival chordomas with intraspinal extension, are described below.

\section{Patient Positioning}

After appropriate anesthesia induction and intubation, the patient is placed in a lateral decubitus position with the head stabilized in Mayfield 3-pin fixation to keep the mastoid at the highest point in the field. The head is tilted laterally to widen the operative corridor and ensure ease of surgical access. The upper shoulder is reflected inferiorly by taping it down and supporting the ipsilateral arm with the airplane rest mounted toward the foot of the bed in a caudal fashion. An inverted hockey stick incision is marked, beginning from the mastoid, moving up to the superior nuchal line, and then turning toward the midline and extending inferiorly along the midline to the $\mathrm{C} 4 \mathrm{spi}-$ nous process. Significant disruption of the ventrolateral musculoligamentous structures at the CCJ, drilling of the atlantooccipital and atlantoaxial joints, and removal of the odontoid and anterior $\mathrm{Cl}$ arch lead to significant instability, necessitating unilateral, or at times bilateral, craniocervical fusion. The larger, hockey stick-shaped incision enables access for a fusion procedure to be performed during the same operative session and through the same incision.

\section{Early Dissection, VA Exposure, and Mobilization}

The initial muscular dissection is performed subperiosteally in a superior-to-inferior direction. Once the suboccipital triangle is exposed, the muscular attachments to the $\mathrm{C} 1$ transverse process are released to gain access to its contents, which include the VA and the $\mathrm{C} 1$ nerve root. The third segment of the VA $\left(\mathrm{V}_{3}\right)$ is typically identified by 3 important bony landmarks: the posterior tubercle of $\mathrm{C} 1$, the J-groove (sulcus arteriosus) on the superior aspect of the posterior arch, and the $\mathrm{C} 1$ transverse process. Notably, it is important to anticipate the possibility of a developmental CCJ anomaly, including occipitalization of the atlas with dural entry of the VA between the $\mathrm{C} 1$ and $\mathrm{C} 2$ vertebrae, transformation of the sulcus arteriosus into a bony tunnel, or sharp anteromedial turning of the VA around the arch of $\mathrm{Cl}$ that makes it more susceptible to intraoperative injury or occlusion.

The initial dissection over the $\mathrm{C} 1$ posterior arch is extended to the inferior margin and subsequently extended superiorly to reach the J-groove. Further dissection of the VA continues subperiosteally until the horizontal segment of $\mathrm{V}_{3}$ is identified in the J-groove; this prevents unnecessary bleeding from the perivertebral venous plexus. The C2 nerve root is identified next and followed laterally to delineate the vertical segment of $\mathrm{V}_{3}$. Mobilization of the VA from the $\mathrm{C} 1$ transverse foramen involves 3 important steps: division of the $\mathrm{C} 2$ nerve root, unroofing of the $\mathrm{C} 1$ transverse foramen, and sacrifice of the muscular and posterior meningeal branches of the VA. Caution is advised to assess for an aberrant extradural origin of the PICA to avoid complications. Care is also taken to avoid injury to the ipsilateral internal jugular vein, which lies immedi- 

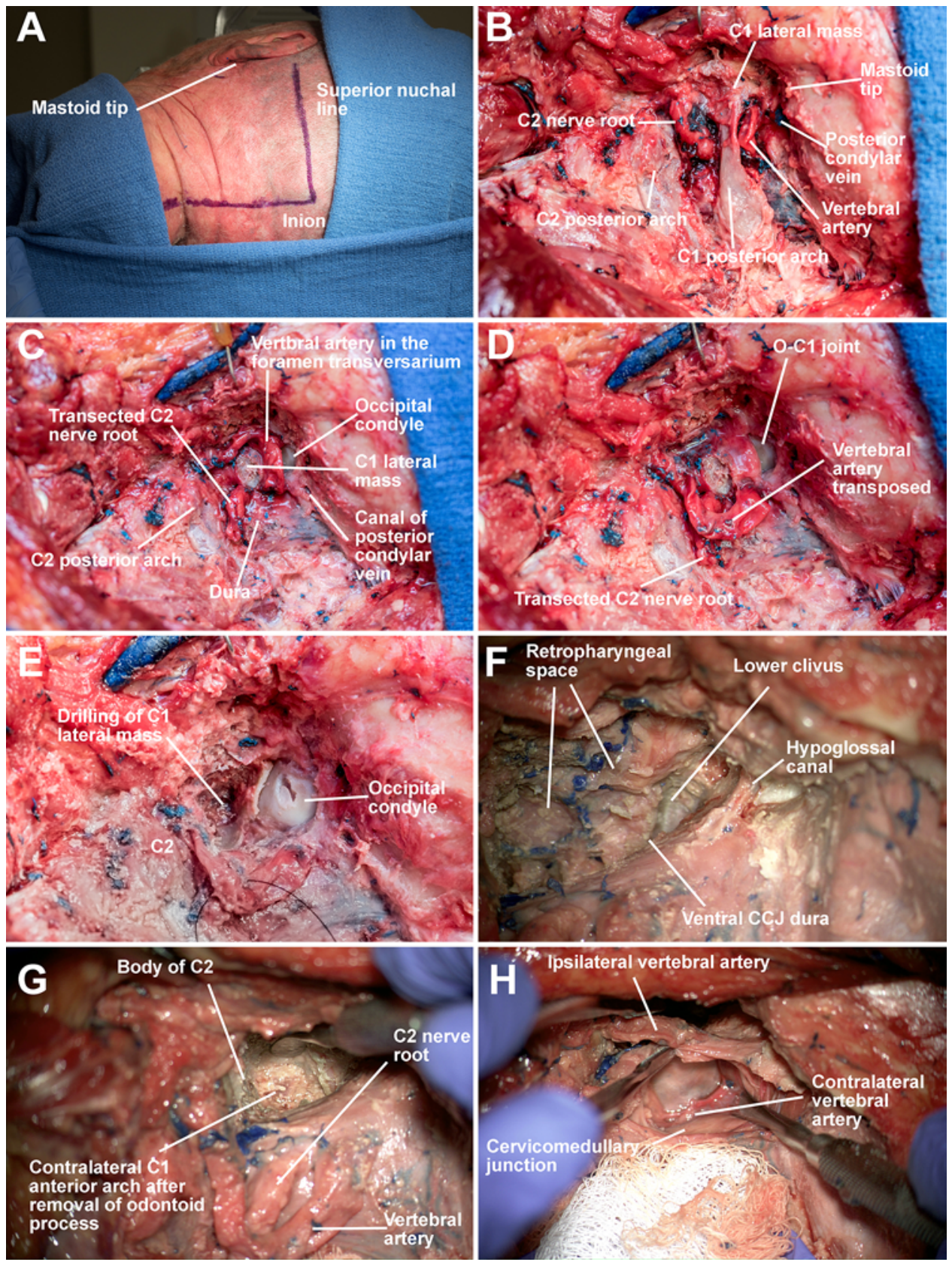

FIG. 1. A and B: Cadaveric dissection illustrating a left-sided hockey stick incision for the ELTO approach (A) and the $V_{3}$ segment of the left VA in the J-groove and the $\mathrm{C} 2$ nerve root below the $\mathrm{C} 1$ posterior arch after the elevation of a single musculocutaneous flap laterally (B). C: The posterior arch of $\mathrm{C} 1$ is removed as far laterally as the lateral mass, the foramen transversarium is drilled posteriorly, and the VA is decompressed. D: The C2 nerve root is transected, and the VA is transposed to expose the occipital condyle (O)-C1 lateral mass articulation. E: The condylar-C1 joint is opened, and the lateral mass of C1 is drilled away, anteriorly toward the anterior arch of C1. F: The occipital condyle is drilled, the hypoglossal canal is opened, and the lower clivus is exposed. G: The ipsilateral $\mathrm{C} 1$ anterior arch is drilled, the odontoid process is removed down to its base, and all the surrounding ligaments are dissected away to expose the longus colli muscle. Then the anterior arch of $\mathrm{C} 1$ is followed toward the contralateral side until it curves backward behind the ventral CCJ dura. $\mathrm{H}$ : The dura is opened in a curvilinear fashion posterior to the ipsilateral VA, and the contralateral intradural VA is exposed. Copyright Department of Neurosurgery, University of Utah. Published with permission. Figure is available in color online only.

ately anterior to the $\mathrm{C} 1$ lateral mass. After transposition of the $\mathrm{V}_{3}$ segment of the VA, the occipital condyle, $\mathrm{C} 1$ lateral mass, and $\mathrm{C} 2$ superior facet come into the direct line of sight for further drilling.

\section{Suboccipital Craniotomy, Condylar Resection, Complete Facetectomy, and Odontoid Resection}

Once the suboccipital bone is exposed subperiosteally, posterior to the digastric groove and mastoid tip, a small 
retrosigmoid suboccipital craniectomy is performed using a high-speed drill. Excessive removal of the superomedial aspect of the suboccipital bone, which will be used for screw placement in the fusion procedure, is avoided. The mastoid bone is drilled anteriorly and laterally to expose the lower half of the sigmoid sinus and jugular bulb. Inferiorly, the foramen magnum rim is removed using careful dissection, exposing the dural entry point of the VA. Subsequently, the posterior $\mathrm{Cl}$ arch and $\mathrm{C} 1$ lateral mass and condylar joint (complete facetectomy) are carefully drilled, avoiding damage to the VA and proceeding anteriorly to the anterior $\mathrm{C} 1$ tubercle. This maneuver exposes the tip of the odontoid process. Drilling of the ipsilateral $\mathrm{C} 2$ lamina and superior articular process of $\mathrm{C} 2$ exposes the inferior portion of the odontoid. Any ligamentous attachment is carefully removed to expose the dural margins. The posteromedial two-thirds of the occipital condyle is drilled to expose the hypoglossal canal, which is located in the anteromedial third of the long axis of the occipital condyle.

Removal of the jugular tubercle, which lies just above and anterior to the hypoglossal canal, expands the surgical corridor an extra 2-4 $\mathrm{mm}$. While drilling the jugular tubercle, care is taken to avoid undue traction on cranial nerves entering the jugular foramen, located just anterosuperior to the jugular tubercle. Exposure is adequate when the transition is identified from cancellous occipital condyle bone to cortical bone surrounding the hypoglossal canal. The extent of bony exposure can be tailored according to the intraoperative image guidance findings to ensure a maximal and anterolateral direct trajectory in line with the long axis of the tumor. Finally, the odontoid process and anterior arch of $\mathrm{C} 1$ are drilled to afford a surgical corridor to the contralateral aspect of the tumor. Depending on the extent of the tumor, the entire odontoid process can be exposed and drilled, revealing the contralateral $\mathrm{C} 1$ anterior arch. Drilling of the contralateral $\mathrm{Cl}$ anterior arch may be continued until it begins to curve toward the contralateral lateral mass. Exposure of the contralateral extracranial VA at $\mathrm{C} 1$ and $\mathrm{C} 2$ is facilitated, and the lesion is removed from this region. The extradural portion of the tumor is resected at this stage before dural opening.

\section{Dural Opening, Tumor Dissection, and Repair}

The dura mater is incised in a curvilinear fashion to expose the lateral skull base. If the dura is infiltrated by the tumor, it is excised, but a small dural cuff is left around the dural entry point of the ipsilateral VA. The tumor is subsequently decompressed and gently dissected off vital neurovascular structures, maintaining a good arachnoid plane. The brainstem-tumor interface is visualized adequately using this approach, which gives adequate vascular control for any potential bleeding. Typically, this exposure provides good visual access from the ipsilateral ninth cranial nerve to the contralateral seventh cranial nerve superiorly and below to the $\mathrm{C} 2$ and $\mathrm{C} 3$ nerve roots. Division of the dorsal rootlets of the $\mathrm{C} 1$ and $\mathrm{C} 2$ nerves, along with division of the dentate ligaments, provides unhindered direct access to the ventral brainstem and upper cervical spine. The primary advantage of this extensive bone drilling is that it provides adequate access to contra- lateral tumor so that a radical resection can be completed using a single operative corridor.

Once adequate microscopic resection of the tumor is achieved, a $30^{\circ}$ endoscope is often used to inspect for any residual tumor around the corners. The dural defect is repaired with a fascial graft and reinforced with autologous fat graft and fibrin glue. The muscles are closed in multiple layers, and the importance of optimal fascial closure cannot be overemphasized. A lumbar drain is placed for at least 72 hours after surgery.

\section{Occipitocervical Fusion Procedures}

CCJ stability is governed by multiple intrinsic ligaments, including the posterior and anterior atlantooccipital and atlantoaxial capsular ligaments; the transverse, alar, and apical ligaments; and the tectorial membrane. ${ }^{19}$ In the ELTO approach, these critical ligamentous attachments are removed, along with resection of the ipsilateral $\mathrm{C} 1$ lateral mass, the $\mathrm{C} 1$ anterior arch, and portions of the odontoid and the occipital condyle. This results in severe destabilization of the CCJ and necessitates concurrent occipitocervical fusion. Notably, the procedure may be staged to reduce operative time, allow recovery in case of significant blood loss during tumor resection, and help ensure the adequacy of tumor resection by allowing for postoperative imaging without hardware artifact. When a staged fusion procedure is planned, we typically keep the patient sedated in a hard cervical collar until the second stage can be completed. For the fusion procedure itself, the patient is positioned prone with the head in a neutral position. Neuromonitoring is critical for both the procedure and positioning. The prior incision is used for either unilateral or bilateral instrumentation, thereby avoiding a separate incision. We prefer using a screw-rod construct for stabilization whenever feasible.

\section{Results}

\section{Morphometric Measurements}

Exposure of the ventral CCJ via the ELTO approach as described above was performed in 7 cadaveric heads, allowing for the morphometric evaluation of the surgical corridor. Measurements of the working distances, angles, and distances between surrounding relevant anatomical structures are summarized in Table 1. After initial identification of the VA in the $\mathrm{C} 1$ transverse foramen, the mean distance from this transverse foramen to the dural entrance of the ipsilateral VA was $23.9 \pm 2.9 \mathrm{~mm}( \pm \mathrm{SD})$. From here, the distance to expose the ipsilateral aspect of the dens was $20.9 \pm 1.9 \mathrm{~mm}$. By drilling the odontoid process and aggressively debriding surrounding ligamentous structures, the viewing angle to the contralateral aspect of the dens was widened. With additional drilling of the contralateral $\mathrm{Cl}$ anterior arch, this reduced the distance from the ipsilateral transverse foramen to the contralateral $\mathrm{VA}$ at its dural entrance to $45.1 \pm 3.4 \mathrm{~mm}$ and increased the anteroposterior prevertebral working angle to $45.5^{\circ} \pm$ $8.3^{\circ}$. Notably, without a large epidural mass displacing the thecal sac and its contents, the contralateral extradural VA was difficult to identify in the fixed cadaveric specimens. 
TABLE 1. Morphometric measurements for the cadaveric head dissection for the ELTO approach

\begin{tabular}{lcc}
\hline \multicolumn{1}{c}{ Anatomical Landmarks } & Mean & SD \\
\hline $\begin{array}{l}\text { Transverse foramen C1 to ipsilateral VA dural } \\
\text { entrance, mm }\end{array}$ & 23.9 & 2.9 \\
\hline $\begin{array}{l}\text { Transverse foramen C1 to contralateral VA dural } \\
\text { entrance, mm }\end{array}$ & 45.1 & 3.4 \\
\hline $\begin{array}{l}\text { Ipsilateral VA dural entrance to ipsilateral side of } \\
\text { odontoid base, mm }\end{array}$ & 20.9 & 1.9 \\
\hline $\begin{array}{l}\text { Odontoid (base) contralateral side to contralateral } \\
\text { VA dural entrance, mm }\end{array}$ & 18.0 & 1.7 \\
\hline $\begin{array}{l}\text { Odontoid width at base (flat on C2), mm } \\
\text { Anteroposterior working angle, }{ }^{\circ}\end{array}$ & 18.3 & 2.1 \\
\hline Craniocaudal working angle to basion, ${ }^{\circ}$ & 45.5 & 8.3 \\
\hline
\end{tabular}

\section{Anatomical Observations}

Transposition of the $\mathrm{V}_{3}$ segment of the VA with complete removal of the lateral mass and unilateral anterior arch of $\mathrm{C} 1$ allowed for excellent exposure of the odontoid process at a relatively short working distance and favorable working angle (Table 1). Complete amputation of the odontoid process and its surrounding ligaments exposed the ventral CCJ dura and allowed access for drilling the contralateral C1 anterior arch. Despite the extensive bony removal, it should be noted that, in the cadaveric specimens, visualization of the extradural portion of the contralateral VA was extremely difficult without retraction of the thecal sac. However, in our experience, this is not representative of the extent of exposure in patients whose unfixed tissues are often dramatically displaced by large lesions in this location. In clinical practice, drilling of the odontoid process exposes the surgical corridor to the contralateral VA fashioned by lesional mass effect. When the dura is opened, the full course of the contralateral intradural VA can easily be visualized without any significant retraction of the neuraxis. Finally, by combining removal of the lateral mass and anterior arch of $\mathrm{C} 1$ in the cadavers with removal of the ipsilateral occipital condyle to the hypoglossal canal, we were able to access and drill the lower third of the clivus, medial to the jugular foramen, from an inferior-to-superior trajectory.

\section{Case Illustrations \\ Case 1}

This patient was an otherwise healthy 3-year-old girl with neck pain initially attributed to myofascial pain resulting from a recent bout of pertussis. When the pain persisted despite conservative therapies, she underwent MRI of the cervical spine and brain, which showed a destructive lesion at the CCJ extending from the tip of the clivus to the axis. The mass extended behind the $\mathrm{Cl}$ lamina and into the C1-2 neural foramina with heterogeneous enhancement. The patient underwent a left-sided far lateral suboccipital craniectomy for debulking of her tumor, which was diagnosed as an epithelioid sarcoma. After consultations at multiple institutions, she was referred to our institution for further operative intervention without having undergone further treatment apart from oral corticosteroids.

Repeat imaging at our hospital showed significant enlargement of the mass in the 2-month interval since her initial scans, with the mass measuring $4.0 \times 4.6 \times 4.1$ $\mathrm{cm}$. The lesion extended from the lower part of the clivus down to the odontoid process craniocaudally and showed significant extension toward the left side involving the left occipital condyle and C1 lateral mass. There was significant compression on the ventral lower brainstem and upper cervical cord (Fig. 2). The patient had also developed noticeable left-sided weakness, although this improved with corticosteroid therapy such that she regained anti-
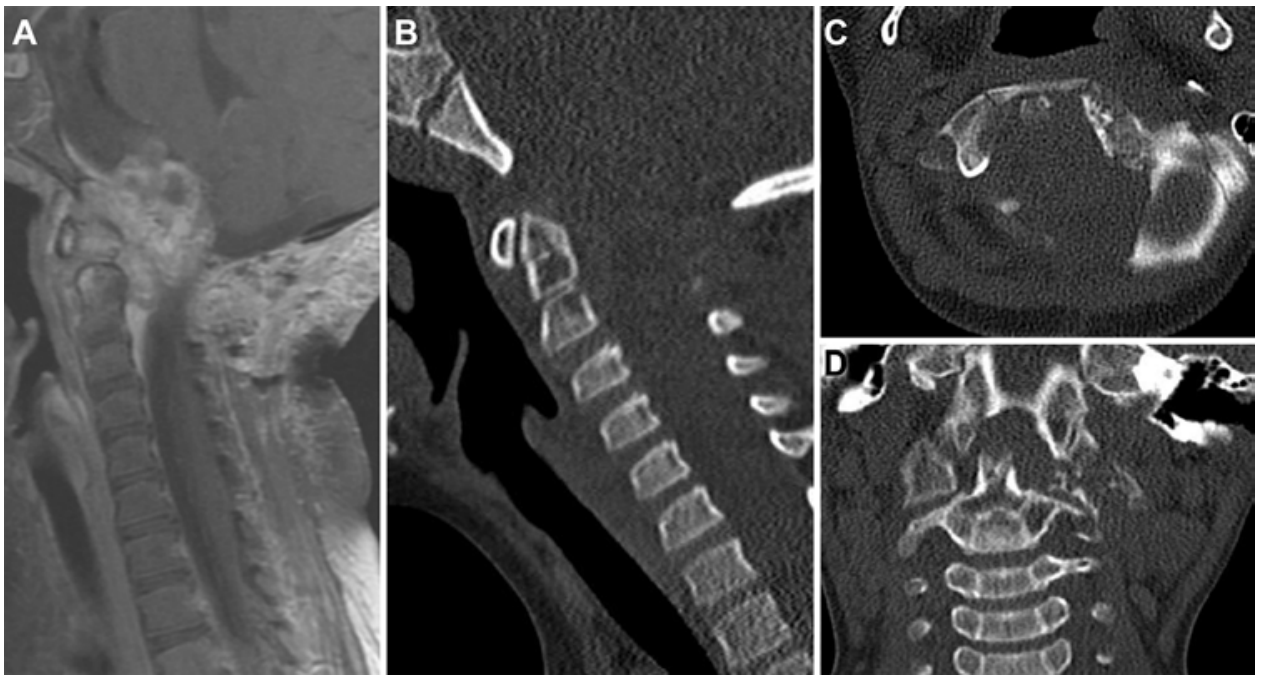

FIG. 2. Case 1. A: Preoperative sagittal postcontrast T1-weighted MR image demonstrating an infiltrative destructive lesion at the skull base extending from the tip of the clivus to the axis with both intra- and extradural components. B-D: Preoperative sagittal $(B)$, axial (C), and coronal (D) noncontrast CT scans showing the bony destructive lesion involving the skull base and evidence of prior surgery. 


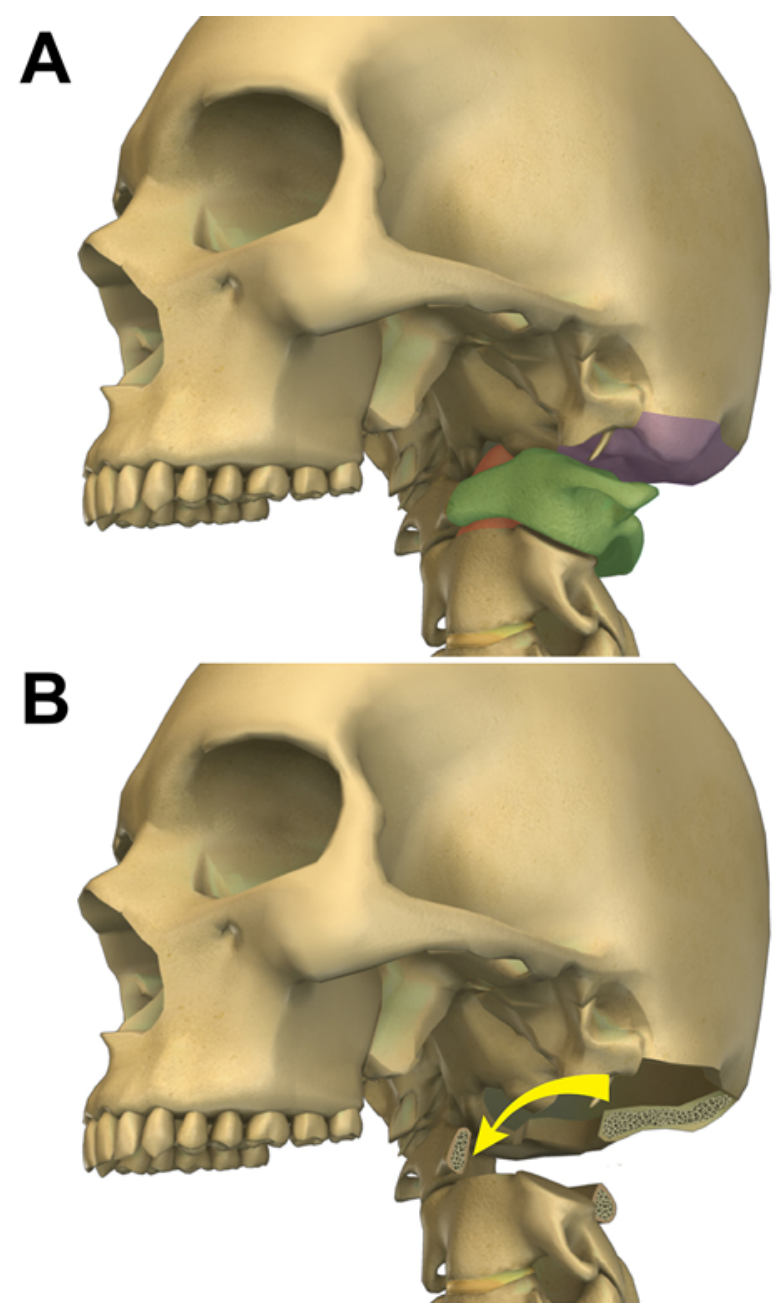

FIG. 3. Illustrations of the ELTO approach demonstrating bony removal (A) and the ventrolateral trajectory (arrow, B) to the anterior craniovertebral junction. Copyright Department of Neurosurgery, University of Utah. Published with permission. Figure is available in color online only.

gravity control in her extremities. The results of her physical examination on arrival were otherwise normal, with the exception of left-sided tongue deviation with associated atrophy.

The patient was admitted to the pediatric intensive care unit in preparation for surgery. Despite continued steroid therapy, her condition declined and she developed left hemiplegia in the days preceding surgery. Five days after admission, the patient underwent a left ELTO approach. Given the significant leftward lateral extension and the involvement of the occipital condyle and $\mathrm{C} 1$ lateral mass, tumor extirpation was followed by posterior occipitocervical fusion (Fig. 3). The total operative time was 8 hours with an estimated blood loss of $200 \mathrm{ml}$.

Postoperative imaging demonstrated radical resection of the patient's tumor along with involved bone (Fig. 4). The final pathology report revealed a poorly differentiated chordoma, in contrast to the initial reports from the previous biopsy. The tumor contained pleomorphic epithelioid cells, some of which contained vacuolated cytoplasm. Im- munostaining was positive in the tumor for broad-spectrum cytokeratins and brachyury, a definitive diagnostic marker of chordoma. INI-1 staining was largely lost in the tumor, and molecular analysis of the lesion demonstrated a BRCA-1 mutation. Postoperatively, the patient remained hemiplegic on the left without a new neurological deficit; however, she required tracheostomy placement for prolonged intubation due to poor respiratory status. Notably, nearly 2 months after surgery, the patient was readmitted from a rehabilitation facility for a brainstem hemorrhage of an unclear cause and presented with neurological deterioration. Although she underwent urgent evacuation, she remained in poor clinical status and was discharged to hospice where she died.

\section{Case 2}

This patient initially presented as an otherwise healthy 3 -year-old boy with progressively worsening headaches. MRI of the brain for diagnostic workup demonstrated evidence of a large, destructive skull base lesion extending from the posterior tip of the clivus inferiorly to the anterior and posterior aspects of the $\mathrm{C} 1$ arch and body of $\mathrm{C} 2$ and C3. There was significant bilateral extension of the lesion beyond the midline and mass effect on the cervicomedullary junction (Fig. 5A-D). At the time of presentation, the patient demonstrated no focal neurological deficits, and he was initially treated with dexamethasone.

CT angiography was performed prior to surgery to better delineate the vascular and bony anatomy. The patient underwent a right-sided ELTO approach for tumor resection, given the significant bilateral and craniocaudal extension. The patient was kept in a cervical collar, and occipitocervical fusion was planned in the following days. Resection lasted for 9 hours with an estimated blood loss of $200 \mathrm{ml}$. Postoperative imaging demonstrated a small residual lesion in the right $\mathrm{C} 2$ lateral mass, which was removed during the subsequent occipitocervical fusion. Repeat postoperative imaging revealed complete extirpation of the tumor and involved bone (Fig. 5E-H). The pathology results were consistent with a chordoma, demonstrating large epithelioid cells with prominent cell borders and a myxoid stroma. Immunohistochemical staining performed on the tumor revealed positive staining for EMA, S100 protein, and broad-spectrum cytokeratins. Postoperatively, a pseudomeningocele developed at the surgical site; it was ultimately treated with ventriculoperitoneal shunt placement after failed conservative management. The patient recovered very well with no new neurological deficit and was discharged home on postoperative day 30. At his recent 2-year clinical and radiological follow-up, there was no evidence of tumor recurrence.

\section{Case 3}

This patient was a 42-year-old woman who presented with 3 months of intermittent headaches and dysphagia. Her neurological examination revealed deviation of the uvula to the right side, decreased gag reflex, and left tongue deviation. No other motor or sensory deficit was identified. Brain and cervical spine MRI and CT scans showed an enhancing lytic lesion measuring $4.8 \times 3.5 \mathrm{~cm}$ located at the ventral CCJ and involving the lower third of the clivus, the 

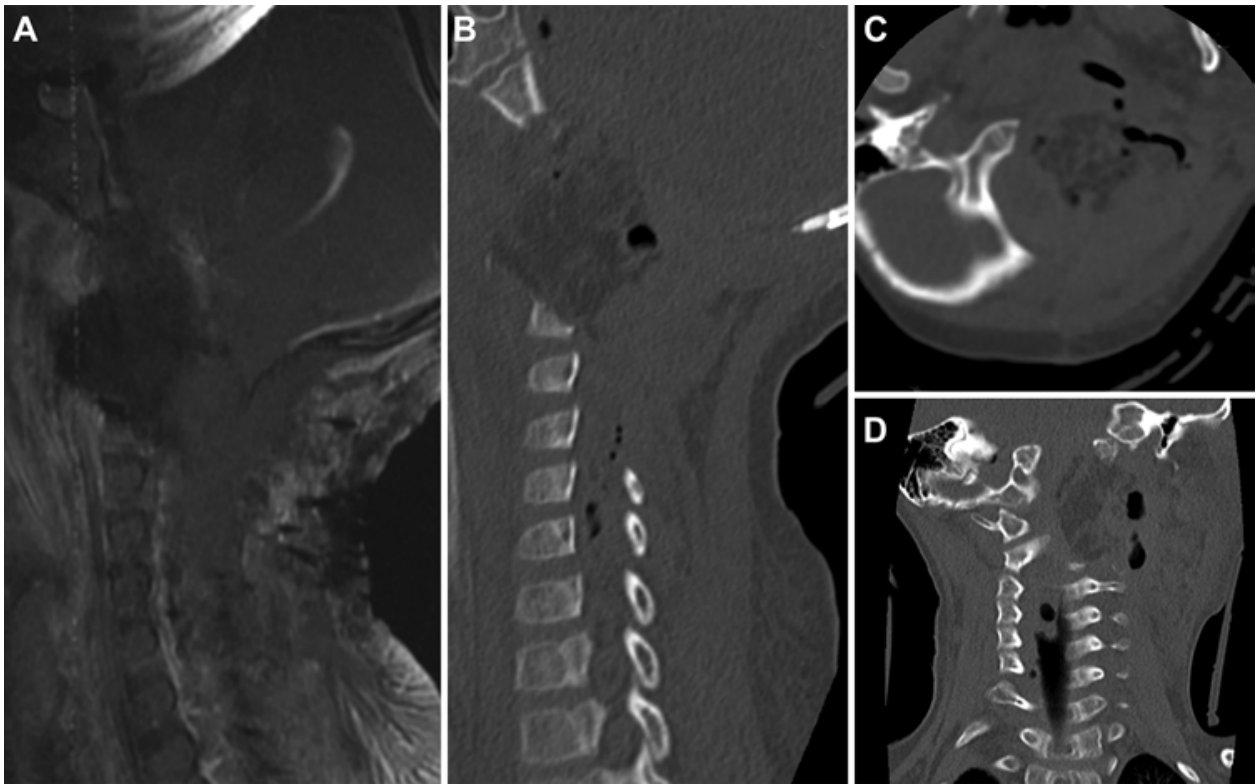

FIG. 4. Case 1. A: Postoperative sagittal postcontrast T1-weighted MR image demonstrating radical removal of the lesion.

B-D: Postoperative sagittal (B), axial (C), and coronal (D) bone window CT scans demonstrating radical resection of the occipital condyle, C1 lateral mass, and odontoid process via the ELTO approach.

$\mathrm{C} 1$ anterior arch, and the tip of the odontoid process. This lesion was slightly eccentric toward the left side, causing mass effect on the cervicomedullary junction (Fig. 6A-D).

The patient underwent a left-sided ELTO approach given the significant rightward extension of the tumor beyond the midline for maximum safe resection (Video 1).

VIDEO 1. Video demonstrating the left ELTO approach for resection of a ventral CCJ chordoma. Copyright Department of Neurosurgery, University of Utah. Published with permission. Click here to view.

The surgical time was 9 hours with an estimated blood loss of $500 \mathrm{ml}$. Surgical pathology results were again consistent with a chordoma, demonstrating fibrous connective tissue infiltrated by a neoplastic population of physaliferous cells within a myxoid matrix forming nests and cords. Immunohistochemistry slices stained positive for EMA, S100, and AE1/3. Postoperative MRI and CT showed gross-total resection (Fig. 6E-I), and the patient was discharged home on postoperative day 5 with no new neurological deficits. There was no evidence of tumor recurrence at her 1-year postoperative follow-up.

\section{Discussion}

Surgical approaches to the lower clivus and upper cervical region have evolved substantially because of advances in skull base neurosurgery. The basic premise in surgical management of the ventral $\mathrm{CCJ}$ is to obtain a wider soft-tissue exposure and more bony removal without undue retraction on the brainstem, spinal cord, and cranial nerves. In 1972, Hammon and Kempe ${ }^{12}$ first described the lateral suboccipital approach to vertebrobasilar junction aneurysms where the lateral suboccipital bone was removed as far laterally as the posterior margin of the sigmoid sinus without resection of any part of the occipital condyle. $\operatorname{Heros}^{13}$ modified this approach by adding $\mathrm{C} 1$ hemilaminectomy with extension to the sulcus arteriosus as well as removal of bone from the foramen magnum as far laterally as the condylar fossa and the posterolateral margin of the occipital condyle. ${ }^{3}$ Transposition of the VA to widen the surgical corridor for the approach of tumors in the ventral foramen magnum was later described by George et al.,"11 and in 1990 Sen and Sekhar ${ }^{30}$ described the ELTC technique for removal of intradural tumors situated in the anterior foramen magnum and upper cervical spine. Their proposal for drilling $>50 \%$ of the occipital condyle to gain adequate access ventrally to the vertebrobasilar junction, the PICA, and even the contralateral VA, has been extensively corroborated. ${ }^{3,9,20} \mathrm{Al}$-Mefty et al. ${ }^{1} \mathrm{de}-$ scribed the use of a transcondylar approach for removal of extradural benign lesions at the ventral CCJ via drilling the occipital condyle to the hypoglossal canal, the condylar surface of the $\mathrm{C} 1$ lateral mass, and the odontoid process without removal of the anterior arch of C1. In 1999, Salas et al. ${ }^{27}$ described 6 modifications of the ELTC approach, including a transfacetal approach. More recently, CT morphometric analyses obtained in the pediatric population demonstrated $15^{\circ}$ of improvement in the angle of attack by drilling just the posteromedial third of the occiput, regardless of the patient's age or sex. ${ }^{26}$ As the size of the condyle remains stable in relation to the rest of the $\mathrm{CCJ}$, these data may also be generalized to the adult population. ${ }^{26}$

\section{Transoral-Transpharyngeal and Extended Endoscopic Approaches to the Ventral CCJ}

The transoral-transpharyngeal approach was described first to approach a bullet lodged in the ventral CCJ in 1917, when the lateral approaches to the ventral CCJ were more limited..$^{15}$ However, operative morbidity and mortality related to this approach limited its subsequent application 


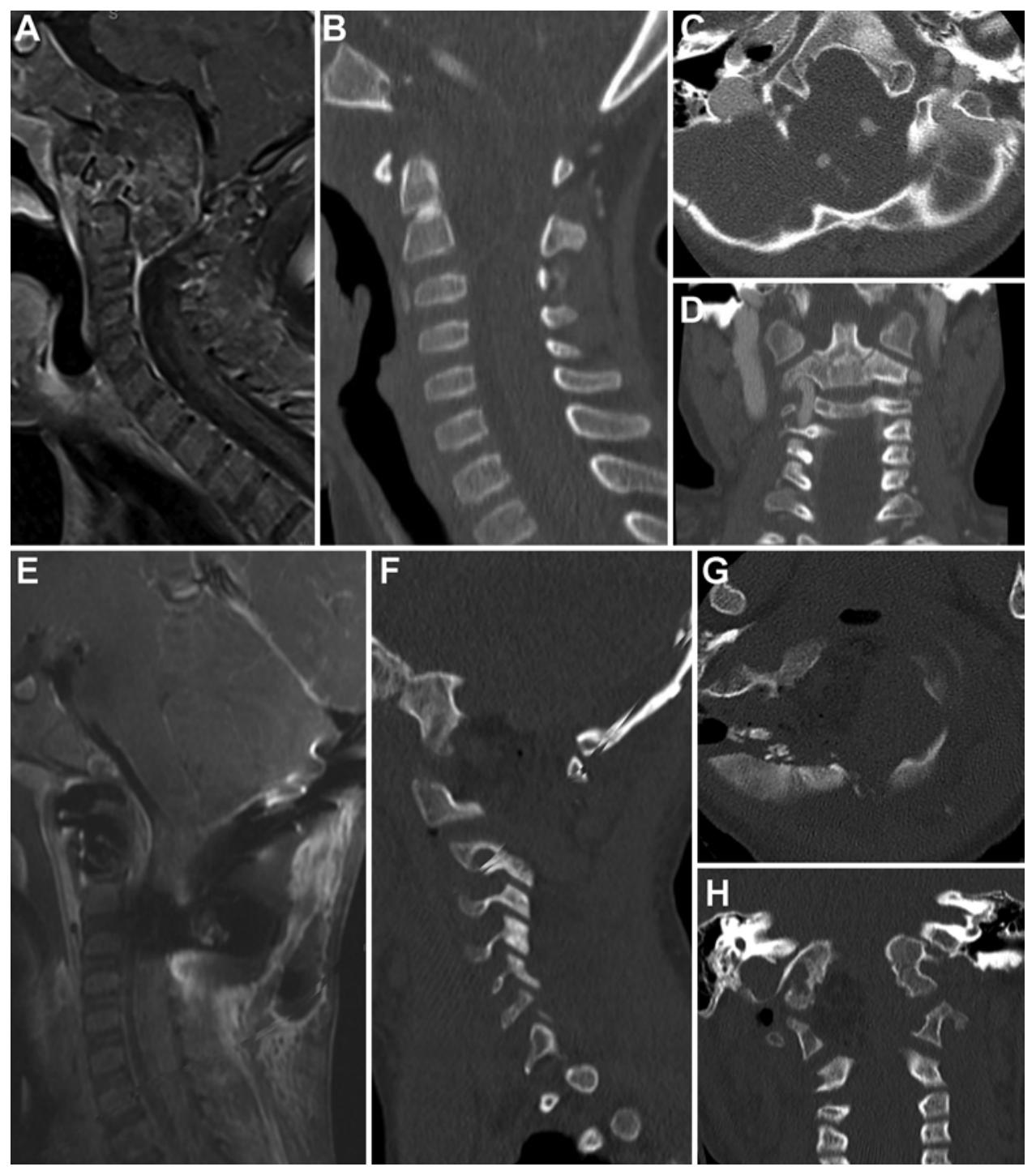

FIG. 5. Case 2. A: Preoperative sagittal postcontrast T1-weighted MR image demonstrating an infiltrative destructive lesion at the skull base with significant ventral brainstem compression, heterogeneous enhancement, and bilateral extension. B-D: Preoperative sagittal (B), axial (C), and coronal (D) noncontrast CT scans demonstrating the destructive lesion centered around the clivus and extending to the upper cervical spine. E-H: Postoperative sagittal postcontrast T1-weighted MR image (E) demonstrating gross-total removal of the lesion. Postoperative sagittal $(F)$, axial $(\mathrm{G})$, and coronal $(\mathrm{H})$ bone window $\mathrm{CT}$ scans demonstrating radical resection of the occipital condyle, C1 lateral mass, and odontoid process (ELTO approach).

until it was refined by Menezes and colleagues to treat irreducible ventral CCJ pathologies..$^{23,24}$ The superior limit of this approach is the tip of the clivus, but the lower third of the clivus can be exposed when the soft palate is divided (transoral-transpalatopharyngeal). The lower extent of the exposure is the $\mathrm{C} 2-3$ interspace, and the lateral limits are the hypoglossal canal and the eustachian tube. ${ }^{8}$

Initial exposure of the $\mathrm{CCJ}$ using a transnasal approach was performed using the microscope. ${ }^{5,33}$ The endoscopic endonasal approach to the ventral CCJ was first reported in 2005 by Kassam et al ${ }^{16}$ for use when removing a pannus at the odontoid process. Although the caudal extent of the extended endoscopic approach to the CCJ is limited when compared with the transoral approach, subsequent reports have suggested that it has a lower risk of oropharyngeal swelling, allows early extubation, avoids soft palate division, and is associated with a lower risk of meningitis. ${ }^{8}$ The inferior limit of the extended endoscopic approach is determined by the nasopalatine line, a line extending from the inferior margin of nasal bone to the posterior margin of the hard palate. The lateral limits for this approach are the paraclival carotid artery superiorly and the eustachian tube inferiorly. Both approaches provide direct access to the lesion in the ventral CCJ, especially for small and discrete lesions, but have several disadvantages, including the long and narrow working distance, clean-contaminated surgical field, and limited lateral exposure related to the VA and jugular bulb in tumors with significant lateral extension. Finally, the need for subsequent surgery for occipitocervical fusion through a different skin incision, 

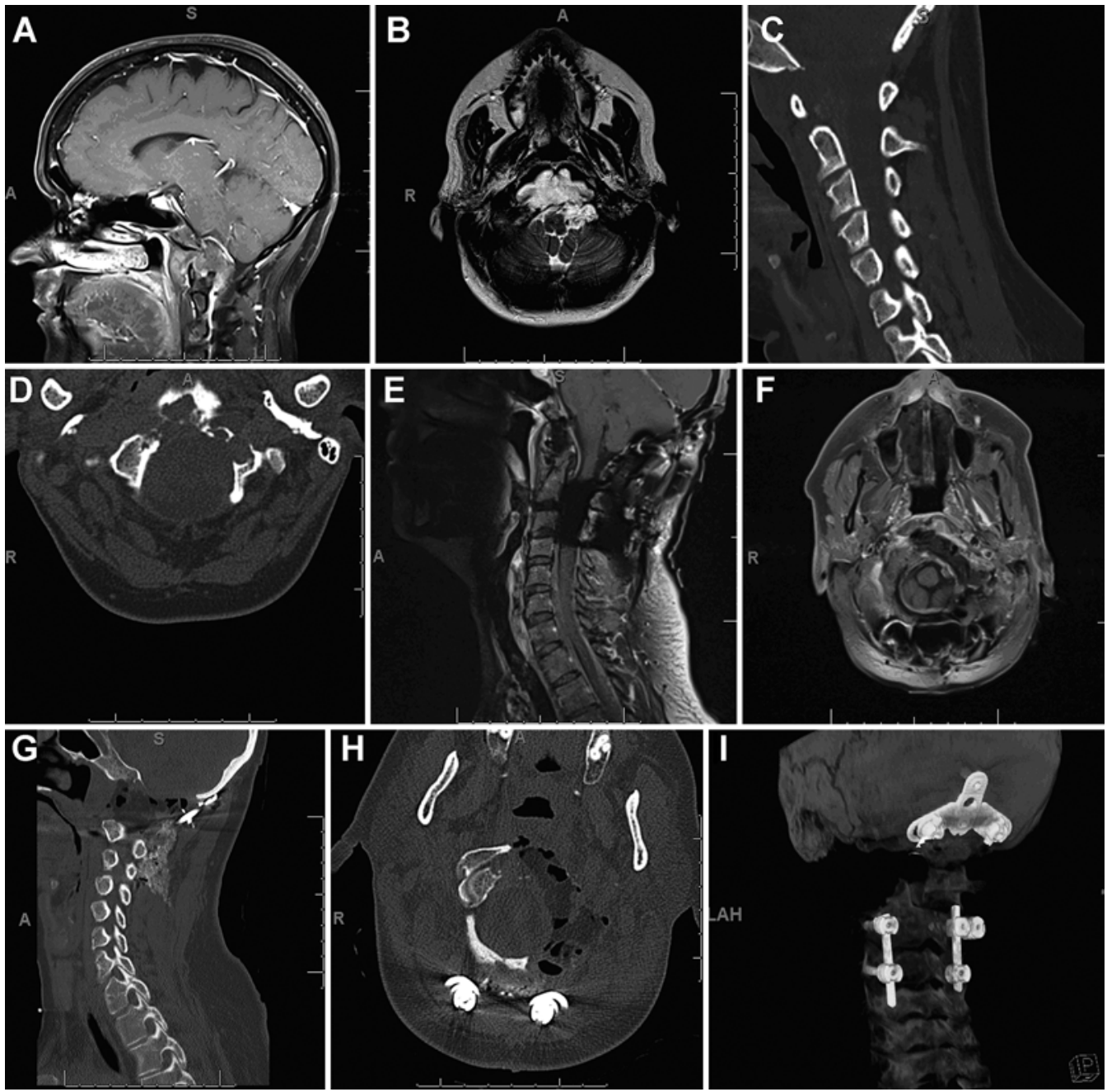

FIG. 6. Case 3. A-D: Preoperative sagittal T1-weighted MR image with gadolinium (A), axial T2-weighted MR image (B), and sagittal (C) and axial (D) CT scans of the CCJ demonstrating an enhancing and lytic lesion located at the ventral CCJ. E-H: Postoperative sagittal $(E)$ and axial $(F)$ T1-weighted MR images with gadolinium, and sagittal $(G)$ and axial $(H)$ CT slices of the CCJ demonstrating gross-total resection of the tumor with bony removal accomplished through a left ELTO approach. I: Threedimensional reconstruction of the $\mathrm{CCJ}$ after gross-total resection.

and the necessary addition with a transoral approach of a mandibular split to widen the surgical corridor when the interdental distance is $<25 \mathrm{~mm}$, are also disadvantages of these approaches. ${ }^{1,30}$

\section{ELTO Approach}

In our experience, the ELTO approach greatly enhances the operative corridor to ventral brainstem and upper cervical spine lesions. Like other traditional lateral approaches to the CCJ, the ELTO approach provides early vascular control of the ipsilateral extradural VA and bilateral intradural VA, early visualization of the tumor-neuraxis interface, a wide sterile surgical field, and fusion through the same surgical incision. ${ }^{1}$ However, the greatest advantage of the ELTO approach is the extension of the surgical corridor to the contralateral side extradurally via removal of the $\mathrm{Cl}$ anterior arch, the odontoid tip, and the surrounding ligaments. This allows safe removal of lesions with signifi- cant bilateral extension through a single surgical corridor, but it results in extensive CCJ instability. Although some controversy exists in the literature regarding the indications for occipitocervical fusion following the far lateral or extreme lateral transcondylar approaches, ${ }^{2,21,27,31}$ in the ELTO approach there is a clear indication for surgical stabilization given that at least $50 \%$ of the occipital condyle, occiput-C1 joint, entire $\mathrm{C} 1$ lateral mass, odontoid process, and all surrounding ligaments are removed.

In our illustrative clinical cases, we achieved radical resection of extradural clival chordomas with or without intradural extension in both children and adult patients via a unilateral operative corridor. All 3 illustrative cases presented share significant extension beyond midline either unilaterally, as shown in cases 1 and 3, or bilaterally as shown in case 2. Although chordomas are often soft tumors, using the ELTO approach allowed gross-total removal of all the lesions using a single operative cor- 
ridor rather than a combined anterior and posterolateral approach. The superolateral limit for this approach is the hypoglossal canal; however, the lower third of the clivus can be reached from an inferosuperior trajectory medial to the jugular foramen and a wide working angle of $35^{\circ}$. Anteriorly, the anatomical boundaries are the retropharyngeal space and carotid sheath. Inferiorly, bone removal can be extended as far as necessary to achieve extirpation of the lesion. Lesions confined to the midline in the ventral CCJ with no inferior extension below the odontoid base or lateral extension beyond the hypoglossal canal and the internal carotid artery can be addressed via an extended endonasal approach. In our experience, the ELTO approach may be indicated for lesions affecting the ventral CCJ that have significant lateral extension beyond the midline, thus rendering gross-total resection via an anterior approach alone unlikely. Moreover, the ELTO approach may be used to tackle any number of neoplastic and nonneoplastic pathologies of the ventral CCJ. These include chordomas, chondrosarcomas, meningiomas, various congenital anomalies, and a host of inflammatory bony lesions, such as basilar invagination or rheumatoid arthritis.

In contrast to the existing controversy in the literature regarding the indications for an occipitocervical fusion procedure following the far lateral or extreme lateral transcondylar approach,2,21,27,31 the ELTO approach is a CCJ destabilizing procedure because it requires removal of at least $50 \%$ of the occipital condyle, occiput-C1 joint, entire C1 lateral mass, odontoid process, and all surrounding ligaments along with the lesion. This procedure will render the CCJ unstable and necessitates a simultaneous or staged occipitocervical fusion procedure.

\section{Conclusions}

Careful selection of a surgical approach, meticulous microsurgical technique, and optimal reconstruction of the skull base are basic tenets of skull base surgery that minimize complications while achieving radical tumor removal. The ELTO approach described herein expands the armamentarium of skull base surgeons by providing a very wide, short, and direct operative trajectory to ventral and ventrolateral skull base lesions with adequate degrees of freedom to maximize tumor removal safely, even for tumors extending to the contralateral side. The ELTO approach provides an excellent alternative to ventrally based approaches to the CCJ when the likelihood of removing these tumors in a single stage is low. Nevertheless, choosing the appropriate surgical corridor to tackle a CCJ tumor should be individualized for each patient based on the superior and lateral extent of the lesion.

\section{Acknowledgments}

We thank Kristin Kraus, MSc, for editorial assistance in preparing this paper.

\section{References}

1. Al-Mefty O, Borba LA, Aoki N, Angtuaco E, Pait TG: The transcondylar approach to extradural nonneoplastic lesions of the craniovertebral junction. J Neurosurg 84:1-6, 1996

2. Bejjani GK, Sekhar LN, Riedel CJ: Occipitocervical fusion following the extreme lateral transcondylar approach. Surg Neurol 54:109-116, 2000

3. Bertalanffy H, Seeger W: The dorsolateral, suboccipital, transcondylar approach to the lower clivus and anterior portion of the craniocervical junction. Neurosurgery 29:815821,1991

4. Chambers KJ, Lin DT, Meier J, Remenschneider A, Herr M, Gray ST: Incidence and survival patterns of cranial chordoma in the United States. Laryngoscope 124:1097-1102, 2014

5. Couldwell WT, Weiss MH, Rabb C, Liu JK, Apfelbaum RI, Fukushima T: Variations on the standard transsphenoidal approach to the sellar region, with emphasis on the extended approaches and parasellar approaches: surgical experience in 105 cases. Neurosurgery 55:539-550, 2004

6. Crumley RL, Gutin PH: Surgical access for clivus chordoma. The University of California, San Francisco, experience. Arch Otolaryngol Head Neck Surg 115:295-300, 1989

7. de Almeida JR, Zanation AM, Snyderman CH, Carrau RL, Prevedello DM, Gardner PA, et al: Defining the nasopalatine line: the limit for endonasal surgery of the spine. Laryngoscope 119:239-244, 2009

8. Dlouhy BJ, Dahdaleh NS, Menezes AH: Evolution of transoral approaches, endoscopic endonasal approaches, and reduction strategies for treatment of craniovertebral junction pathology: a treatment algorithm update. Neurosurg Focus 38(4): $\mathrm{E} 8,2015$

9. Dowd GC, Zeiller S, Awasthi D: Far lateral transcondylar approach: dimensional anatomy. Neurosurgery 45:95-100, 1999

10. Fraser JF, Nyquist GG, Moore N, Anand VK, Schwartz TH: Endoscopic endonasal transclival resection of chordomas: operative technique, clinical outcome, and review of the literature. J Neurosurg 112:1061-1069, 2010

11. George B, Dematons C, Cophignon J: Lateral approach to the anterior portion of the foramen magnum. Application to surgical removal of 14 benign tumors: technical note. Surg Neurol 29:484-490, 1988

12. Hammon WM, Kempe LG: The posterior fossa approach to aneurysms of the vertebral and basilar arteries. J Neurosurg 37:339-347, 1972

13. Heros RC: Lateral suboccipital approach for vertebral and vertebrobasilar artery lesions. J Neurosurg 64:559-562, 1986

14. Jones PS, Aghi MK, Muzikansky A, Shih HA, Barker FG II, Curry WT Jr: Outcomes and patterns of care in adult skull base chordomas from the Surveillance, Epidemiology, and End Results (SEER) database. J Clin Neurosci 21:14901496, 2014

15. Kanavel A: Bullet located between the atlas and the base of the skull: technique of removal through the mouth. Surg Clin Chicago 1:361-366, 1917

16. Kassam AB, Snyderman C, Gardner P, Carrau R, Spiro R: The expanded endonasal approach: a fully endoscopic transnasal approach and resection of the odontoid process: technical case report. Neurosurgery 57 (1 Suppl):E213, 2005

17. Kawashima M, Tanriover N, Rhoton AL Jr, Ulm AJ, Matsushima T: Comparison of the far lateral and extreme lateral variants of the atlanto-occipital transarticular approach to anterior extradural lesions of the craniovertebral junction. Neurosurgery 53:662-675, 2003

18. Koutourousiou M, Gardner PA, Tormenti MJ, Henry SL, Stefko ST, Kassam AB, et al: Endoscopic endonasal approach for resection of cranial base chordomas: outcomes and learning curve. Neurosurgery 71:614-625, 2012

19. Lopez AJ, Scheer JK, Leibl KE, Smith ZA, Dlouhy BJ, Dahdaleh NS: Anatomy and biomechanics of the craniovertebral junction. Neurosurg Focus 38(4):E2, 2015

20. Margalit NS, Lesser JB, Singer M, Sen C: Lateral approach to anterolateral tumors at the foramen magnum: factors 
determining surgical procedure. Neurosurgery 56 (2 Suppl):324-336, 2005

21. Mazur MD, Couldwell WT, Cutler A, Shah LM, Brodke DS, Bachus K, et al: Occipitocervical instability after far-lateral transcondylar surgery: a biomechanical analysis. Neurosurgery 80:140-145, 2017

22. McMaster ML, Goldstein AM, Bromley CM, Ishibe N, Parry DM: Chordoma: incidence and survival patterns in the United States, 1973-1995. Cancer Causes Control 12:1-11, 2001

23. Menezes AH, Graf CJ, Hibri N: Abnormalities of the craniovertebral junction with cervico-medullary compression. A rational approach to surgical treatment in children. Childs Brain 7:15-30, 1980

24. Menezes AH, VanGilder JC: Transoral-transpharyngeal approach to the anterior craniocervical junction. Ten-year experience with 72 patients. J Neurosurg 69:895-903, 1988

25. Menezes AH, VanGilder JC, Graf CJ, McDonnell DE: Craniocervical abnormalities. A comprehensive surgical approach. J Neurosurg 53:444-455, 1980

26. Patel AJ, Gressot LV, Cherian J, Desai SK, Jea A: Far lateral paracondylar versus transcondylar approach in the pediatric age group: CT morphometric analysis. J Clin Neurosci 21:2194-2200, 2014

27. Salas E, Sekhar LN, Ziyal IM, Caputy AJ, Wright DC: Variations of the extreme-lateral craniocervical approach: anatomical study and clinical analysis of 69 patients. J Neurosurg 90 (2 Suppl):206-219, 1999

28. Sekhar LN, Nanda A, Sen CN, Snyderman CN, Janecka IP: The extended frontal approach to tumors of the anterior, middle, and posterior skull base. J Neurosurg 76:198-206, 1992

29. Sen C, Triana AI, Berglind N, Godbold J, Shrivastava RK: Clival chordomas: clinical management, results, and complications in 71 patients. J Neurosurg 113:1059-1071, 2010

30. Sen CN, Sekhar LN: An extreme lateral approach to intradural lesions of the cervical spine and foramen magnum. Neurosurgery 27:197-204, 1990
31. Shin H, Barrenechea IJ, Lesser J, Sen C, Perin NI: Occipitocervical fusion after resection of craniovertebral junction tumors. J Neurosurg Spine 4:137-144, 2006

32. Wanibuchi M, Fukushima T, Zenga F, Friedman AH: Simple identification of the third segment of the extracranial vertebral artery by extreme lateral inferior transcondylartranstubercular exposure (ELITE). Acta Neurochir (Wien) 151:1499-1503, 2009

33. Weiss M: Transnasal transsphenoidal approach, in Apuzzo M (ed): Surgery of the Third Ventricle. Baltimore: Williams \& Wilkins, 1987, pp 476-494

\section{Disclosures}

The authors report no conflict of interest concerning the materials or methods used in this study or the findings specified in this paper.

\section{Author Contributions}

Conception and design: Couldwell, Brockmeyer. Acquisition of data: Alzhrani, Gozal, Eli, Sivakumar, Raheja, Brockmeyer. Analysis and interpretation of data: Alzhrani. Drafting the article: Alzhrani, Gozal, Raheja. Critically revising the article: Couldwell, Alzhrani, Gozal, Brockmeyer. Reviewed submitted version of manuscript: Couldwell, Alzhrani, Gozal, Sivakumar, Brockmeyer. Approved the final version of the manuscript on behalf of all authors: Couldwell.

\section{Supplemental Information \\ Videos \\ Video 1. https://vimeo.com/271653067.}

\section{Correspondence}

William T. Couldwell: University of Utah, Salt Lake City, UT. neuropub@hsc.utah.edu. 